\title{
Schopenhauer e a Religião
}

\author{
Schopenhauer and the Religion
}

\author{
Paul Deussen ${ }^{1}$ \\ Tradução de Guilherme Marconi Germer \\ Doutorando em Filosofia pela Unicamp, bolsista FAPESP. \\ E-mail: guilermeguita@gmail.com
}

\begin{abstract}
Resumo: O que segue é a tradução do artigo Schopenhauer und die Religion, de Paul Deussen, apresentado pelo autor durante o terceiro Congresso da Schopenhauer-Gesellschaft (Sociedade Schopenhauer), em 4 de junho de 1914, e publicado em 1915, na quarta edição dos anuários Schopenhauer-Jahrbuch da Schopenhauer-Gesellschaft. O volume do periódico foi organizado pelo próprio Deussen (Colônia: Verlag der Schopenhauer-Gesellschaft, 1915). A presente tradução é uma homenagem ao autor por ocasião do centenário da elaboração do texto (2014).
\end{abstract}

Palavras-chave: Schopenhauer; Religião; Paul Deussen.

\begin{abstract}
What follows is a translation of the article Schopenhauer und die Religion, of Paul Deussen, presented by the author during the third Congress of Schopenhauer-Gesellschaft (Schopenhauer Society) on June 4, 1914, and published in 1915, in the fourth edition of annuals Schopenhauer-Jahrbuch of Schopenhauer-Gesellschaft. The volume of the journal itself was organized by Deussen (Cologne: Verlag der Schopenhauer-Gesellschaft, 1915). The translation of this text is a tribute to the author on the occasion of the centenary of its drafting (2014).
\end{abstract}

Keywords: Schopenhauer; Religion; Paul Deussen.

\footnotetext{
${ }^{1}$ Além de importante filósofo e filólogo, Paul Deussen (1845-1919) foi "o maior estudioso ocidental do pensamento indiano entre os séculos XVIII e XIX, o único na Alemanha a ocupar uma cátedra de filosofia e a conhecer o sânscrito", conforme Domenico Fazio. Fundador da Schopenhauer-Gesellschaft (Sociedade Schopenhauer) em 1911 e organizador de uma imponente edição das obras completas, dos textos inéditos e das cartas do filósofo em quinze volumes, publicada entre 1911 e 1933, Paul Deussen deve sua descoberta de Schopenhauer a Friedrich Nietzsche, que foi seu "companheiro nos estudos colegiais em Pforta, e depois, por um breve período, na Universidade de Bonn". A despeito da longa amizade, correspondência e mútua referência que perduraram entre ambos por toda a vida, a interpretação que Deussen faz de Schopenhauer segue um "sentido religioso [...] que por uma grande ironia do destino resulta diametralmente oposta à leitura rigorosamente ateia que seu amigo Nietzsche" faz do mesmo (FAZIO, D., KOSSLER, M., LÜTKEHAUS, L. La Scuola di Schopenhauer: Testi e contesti. Lecce: Pensa Multimedia, 2009, p. 189-197). Com base nisto, pode-se afirmar que estes dois autores representam dois dos principais paradigmas da interpretação schopenhaueriana entre a virada do século XIX ao XX, um de cunho religioso e outro de cunho ateu.
} 
Quando, quarenta e três anos atrás, depois de eu completar meus demais exames, para a alegria de meus pais passei também na prova teológica pro licentia concionandi (que em Marburg, segundo o costume da época, se prestava como acesso à Faculdade de Teologia), declarei considerar Schopenhauer como o philosophus christianissimus, "o mais cristão de todos os filósofos". Esta convicção, que se impôs em mim naquele tempo de estudos das escrituras sagradas simultaneamente aos estudos da filosofia schopenhaueriana, não foi abalada após as experiências de uma vida inteira. Muito pelo contrário, ela ganhou ainda mais reforço e confirmação dentro de mim. Sem dúvida alguma, quando afirmo isto não penso no cristianismo histórico, a saber, aquele que aparece em fórmulas míticas, cujo teísmo, herdado do Antigo Testamento, exaspera frequentemente Schopenhauer. Pelo contrário, esta analogia se dirige ao pensamento (Gedanke) propriamente cristão, que se estende muito além do nome do cristianismo e se encontra já na Índia, no vedanta, assim como no budismo. Posteriormente, ele retorna também em Platão, em seus sucessores, e, revestido de um invólucro (Hülle) mítico, no Novo Testamento. Livre deste invólucro, justamente, ele constitui, por fim, o cerne próprio do idealismo filosófico fundado por Kant e trazido à sua mais completa perfeição por Schopenhauer.

Nos Upanishads dos Vedas, em uma das mais belas e profundas passagens que já foram escritas pelas mãos humanas, há uma distinção, em Bribadâranyaka-Upanishad, entre o ser humano que permanece até a morte um "Kâmayamâna", isto é, um "entregue aos desejos" - que deve se submeter a uma purificação ulterior no caminho da viagem da alma (auf dem Wege der Seelenwanderung) - e o "Akâmayamâna", a saber, aquele "livre dos apetites", do qual se diz, em 4, 4, 6, o seguinte: "Quem é sem exigência, livre de exigência, de exigência acalmada, sua própria exigência, cujo espírito não sai da casa, mas é Brahman e em Brahman se abolve"2 ("brahma eva san brahma api-eti"). Este pensamento retorna ainda quando se diz, em Mundaka-Upanishad:

\section{Como as correntes correm e no oceano,}

\footnotetext{
2 „Wer ohne Verlangen, frei von Verlangen, gestillten Verlangens, selbst sein Verlangen ist, dessen
} Lebensgeister ziehen nicht aus, sondern Brahman ist er und in Brahman geht er auf". 
Abandonando nome e forma, desaparecem,

Assim dissolve-se, de nome e forma libertando-se,

O sábio, no mais elevado espírito divino ${ }^{3}$.

Da mesma forma, em Bhagavadgîtâ $\Pi$, 69-72, distingue-se entre os não sábios (Unweisen), que consideram dia o que na realidade é noite, e o sábio, para quem é dia o que àqueles é noite. Por fim, diz-se também do sábio que permanece firme em Brahman que no momento de sua morte o "Brahma-Nirvânam" (o apagar-se em Brahman) é por ele alcançado. Esta mesma expressão "Brahma-Nirvânam" retorna ainda outras duas vezes em Bhag.-G. V, 25, 26, comprovando claramente que ela já era usada nos círculos bramanistas antes de ser apoderada pelo budismo; este que, com o descarte de sua primeira metade, forjou seu conceito de "Nirvânam" ("apagar-se", Auslöschen). A este, porém, faltou justamente o essencial, e todos tiveram que experimentar como seu novo conceito não passava de uma mera mutilação (eine bloße Verstümmelung).

O mesmo pensamento indo-platônico-cristão-schopenhaueriano retorna, posteriormente, em Platão: por exemplo, quando ele descreve, em Teeteto, p. 176, como este mundo está irremediavelmente sucumbido ao mal (dem Bösen verfallen ist). Apontando para o mundo eterno das Ideias, ele prossegue: "Eis porque se deve fugir daqui para lá o mais rápido possível. A fuga, porém, consiste em tornar-se o máximo possível semelhante a Deus; e a semelhança com Deus, em tornar-se justo, sagrado (heilig) e sábio".

Que o mundo inteiro jaz em desordem (im Argen), e que necessitamos de uma salvação (Erlösung) dele é, como todos sabem, a intuição básica não só de nosso Schopenhauer, mas já muito antes dele, do Novo Testamento. A diferença é que este pensamento eterno, enquanto o núcleo do último, apresenta-se revestido por uma casca muito bruta (sehr dicken) e condicionado pela dependência do Antigo Testamento e por outros acidentes históricos. A essência da filosofia medieval consiste no fato de que este núcleo, em meio à inocência de então, foi inoculado nos povos germânicos junto com esta casca, e assim amiúde permaneceu esquecido sob ela. A essência da filosofia moderna, por seu turno, corresponde à tentativa da humanidade de livrar-se desta casca, que passou a ser

3 „Wie Ströme rinnen und im Ozean, / Aufgebend Name und Gestalt, verschwinden, / So geht, erlöst von Name und Gestalt, / Der Weise ein zum göttlich höchsten Geiste“" 
insustentável cientificamente. No entanto, ao descartar a casca, o núcleo também foi, muitas vezes, eliminado.

Ele parecia, de fato, estar além de qualquer salvação, já que após a noite invernal da Idade Média, Copérnico defendeu corretamente o heliocentrismo, e Giordano Bruno refutou a ideia da fixidez da abóboda celeste e reconheceu todas as estrelas fixas, como o Sol - pelo que foi condenado à fogueira. Com isto surgiu a imagem (das Bild) da realidade empírica, que na abertura do segundo tomo de sua obra principal Schopenhauer descreve com as seguintes palavras: "No espaço ilimitado inúmeras esferas resplandecentes, ao redor de cada uma das quais, e iluminadas por sua luz, giram cerca de uma dúzia de esferas menores, quentes por dentro e cobertas com uma crosta fria e robusta, sobre a qual gerouse uma camada de mofo que cria seres vivos e cognoscentes - esta é a verdade empírica, o real, o mundo". No entanto, como Schopenhauer acrescenta, é também uma perspectiva muito precária (ein misslicher Gedanke) estar sobre uma destas inúmeras esferas flutuantes no espaço ilimitado sem saber de onde viemos nem para onde vamos; de modo que nesta dificuldade (Bedrängnis) repousa a irremediável necessidade metafísica humana, com toda a sua urgência. Por um longo tempo pareceu impossível uma salvação desta condição miserável. Depois das descobertas de Copérnico e de Bruno, havia apenas a alternativa de sacrificar a convicção científica à necessidade religiosa, ou essa àquela; até que, por fỉm, surgiu um homem mais forte do que aqueles dois fundadores de nossa visão empírica de mundo. Copérnico e Bruno haviam retirado (weggenommen) o céu e posto em seu lugar o espaço infinito. Então foi Kant que, por sua vez, afastou todo o espaço infinito (wegnahm), ao demonstrar ser ele uma mera forma da representação subjetiva, com o que surgiu a possibilidade da existência de uma outra realidade além da empírica.

O elogio (das Lob) de Kant está por todos os lados. No entanto, são poucos os que ainda hoje conseguem tornar próprios os frutos de sua descoberta. Segundo minha interpretação, apenas na fillosofia de Schopenhauer, cuja pedra angular é a idealidade do espaço e do tempo, eles alcançaram a mais plena maturidade. Um segundo pilar fundamental fornecido por Kant à sua sistemática (como eu demonstrei no Prefácio do segundo volume de nossa edição das obras de Schopenhauer, a partir das palavras do próprio Kant) é o conhecimento de que todo este mundo infinito é apenas fenômeno 
(Erscheinung) e não a coisa em si mesma; e que a coisa em si, já em Kant, revela-se de seu encobrimento (aus seiner Verschleierung hervortritt) apenas no conceito de liberdade, esta que, como deve ser algo em geral, consiste em uma determinação da vontade. Assim nós vemos cintilar já em Kant a grande lição fundamental de Schopenhauer de que a coisa em si, este segredo (Geheimnis) pelo qual todos os filósofos do mundo procuraram, não é senão o que se manifesta em nós como Vontade. Esta vontade, que aparece em tudo o que preenche o espaço, é a coisa em si sem causalidade, e portanto, livre. E a partir desta sua liberdade, segue-se que ela pode querer ou não querer, afirmar ou não afirmar o fenômeno que é este mundo mesmo. Como a Vontade se afirma nós sabemos, uma vez que, como Vontade de vida, ela se determina como uma existência individual e egoísta e se expressa em todos os fenômenos orgânicos e inorgânicos do mundo. Como ela aparece como negação, ou antes, se ela possui em geral e enquanto tal, uma forma de aparição (eine Erscheinungsform), nós não sabemos. Isto é para nós, como Kant dizia, conhecidamente secreto. E então a filosofia poderia apenas aludir (hinweisen) à possibilidade de que a negação da Vontade também possua uma forma de aparição, ceder (überlassen) todo o restante à religião com sua linguagem imagética (Bildersprache) e abster-se de toda palavra extra. Além disto, porém, ela não poderia situar (hervorträten) neste mundo de afirmação certos fenômenos simplesmente inexplicáveis a partir do egoísmo, que é o princípio fundamental deste mundo, e que se apresentam a quem os observa como uma abertura ou transbordamento (ein Durchbruch) da negação na esfera da afirmação. Estes fenômenos são as ações morais da justiça desinteressada, do sacrifício da caridade, da renúncia em todas as suas formas, da abnegação em uma longa tarefa de vida (an eine große Lebensaufgabe), da fidelidade no comprimento de uma determinada promessa e da realização de um certo dever de responsabilidade. Ninguém duvidará do caráter positivo destes fenômenos, e que eles consistem na tarefa (Aufgabe) mais elevada e última de toda esta vida terrena testemunharão a todos seus sentimentos imediatos. No entanto, em uma infeliz ilusão, eles são turvados pelo meu pobre amigo Nietzsche, que toma a negação por algo negativo e sonha com um refinamento da afirmação, que, em última instância, não passa de um refinamento do egoísmo com todas as suas terríveis consequências, com o 
sibaritismo (Genusssucht), sede de vingança, inveja, maldade, tirania e opressão dos fracos e pobres ${ }^{4}$.

Despindo-se da roupagem (Einkleidung) externa, o profundo e íntimo parentesco, ou mesmo, a completa identidade da ética de Schopenhauer com o verdadeiro espírito do cristianismo deixa-se comprovar em quatro lições fundamentais suas; que eu estabeleci em minha Philosophie der Bibel (Filosofia da Bíblia):

1. A não liberdade empírica da Vontade, que expresso filosoficamente soa: a inviolabilidade da lei de causalidade é, em idêntica medida, a intuição fundamental do Novo Testamento e da filosofia de Schopenhauer.

2. Menos superficial ainda é a concordância entre Schopenhauer e a Bíblia em relação àquilo que eu costumo nomear com a expressão kantiana de imperativo categórico. Todos sabem que Schopenhauer luta apaixonadamente contra a forma imperativa da ética kantiana. No entanto, nem todos veem que a forma imperativa é essencial a toda ética, e assim, não menos à de nosso Schopenhauer. Esta forma reside sob a última na medida em que o filósofo, em geral, qualifica as ações da negação, diante das da afirmação, como as mais elevadas (Höhere), louváveis (Erstrebenswertere), “o que a graça e o gênio têm contra elas? O que Bacon de Verulam?”. Em seus primeiros manuscritos, Schopenhauer qualifica a negação da Vontade de vida com uma bela expressão: a da "consciência melhor", um comparativo que, portanto, envolve indubitavelmente um imperativo. Tratando-se do pensador mais honesto que o mundo já conheceu, esta expressão só foi abandonada posteriormente por isto: ele não queria descrever a negação de todo este mundo com uma expressão empírica retirada da realidade.

3. O dogma central do cristianismo consiste, nas palavras do apóstolo Paulo, no renascimento dos velhos homens como novos, ou, nas de Schopenhauer, na viragem da Vontade de vida da afirmação à negação. A identidade destes dois conceitos éticos fundamentais é evidente para todo aquele que quer ver; e quando, com Paulo ou Schopenhauer, este renascimento, esta viragem parece um único ato - uma vez que ambos

\footnotetext{
4 „Aber in einer unseligen Verblendung sind diejenigen befangen, welche mit meinem armen Freunde Nietzsche und hinter ihm herlaufend die Verneinung für etwas Negatives halten und von einer Veredelung der Bejahung träumen, welche zuletzt doch nur eine Veredelung des Egoismus mit allen seinen fürchterlichen Konsequenzen, mit Genußsucht, Eachsucht, Neid, Bosheit, Tyrannei und Unterdrückung des Schwachen und Armen sein würde“.
} 
os professores (Lehrer) da humanidade apresentam-no em suas considerações conceituais como unidade aquilo que, porém, é um processo de uma vida inteira - a eles vale de corretivo (Korrektiv) os seguintes versos do Bhagavadgîtâ:

\section{Purificado por meio de vários nascimentos}

Encontra ele, finalmente, o mais elevado caminho ${ }^{5}$.

4. O Monergismo. Que ao homem enquanto tal só sejam possíveis ações pecadoras, isto é, egoístas; que todas as ações morais de autoabnegação só sejam produzidas por Deus, é indubitavelmente a intuição fundamental dos escritos sagrados, a despeito de sua não compreensão por nossos teólogos liberais. Talvez isto possa ser melhor evidenciado quando eu recordar, com palavras kantianas, que o homem, enquanto coisa em si mesma, é que dá ao homem, enquanto fenômeno, o imperativo categórico, a lei moral. Esta é a culminação da filosofia kantiana, assim como da schopenhaueriana, a saber, na medida em que nossa essência não está limitada neste invólucro de carne e sangue; na medida em que que nós, embora como fenômenos sejamos subordinados ao espaço, portanto, egoístas; ao tempo, portanto, mortais; e à causalidade, portanto, não livres (unfrei) - todo nosso fenômeno empírico é apenas uma aberração (eine Abirrung) de nossa essência em si mesma (von unserem an sich seienden Wesen). Esta, portanto, é sem espaço (raumlos), e então afastada de toda possibilidade do egoísmo e do pecado; sem tempo (zeitlos), e portanto imortal; e sem causalidade, e assim, livre. Esta nossa própria essencialidade em si mesma, sem pecado, imperecível e livre (diese unsere eigene, an sich seiende, sündlose, unsterbliche, freie Wesenheit) é o que, precisamente, é qualificado pela religião, para se ressaltar sua contraposição da maneira mais aguda, como todo nosso ser que está defronte ao fenômeno empírico; em outras palavras, como Deus. É este, justamente, o sentido mais profundo de toda a crença em Deus, da crença de que nosso verdadeiro ser não está limitado à corporalidade, mas que por trás de nossa natureza não livre, mortal e pecadora está nossa essência verdadeira, divina, não pecadora e imortal, à qual nós nos dirigimos

\footnotetext{
5 „Durch mancherlei Geburt geläutert / Geht endlich er den höchsten Gang“.
} 
apenas pelo caminho das ações morais, em um processo de aproximação infinito que cada um de nós completará, mais cedo ou mais tarde, um dia. 